\title{
Competitive Advantage Based on Human Capital and its Impact on Organizational Sustainability: Applied Study in Jordanian Telecommunications Sector
}

\author{
Abdul Azeez Badir Alnidawi ${ }^{1}$, Abdul Sattar Husien Alshemery ${ }^{1} \&$ Manal Abdulrahman ${ }^{1}$ \\ ${ }^{1}$ Business Administration Department, Al-Zaytoonah University, Amman, Jordan \\ Correspondence: Abdul Azeez Badir Alnidawi, Business Administration Department, Al-Zaytoonah University, \\ Amman, Jordan. Tel: 962-79-998-7302. E-mail: dr54azezalnidawy@yahoo.com
}

Received: October 14, 2016

Accepted: December 13, 2016 Online Published: January 25, 2017

doi:10.5539/jms.v7n1p64

URL: http://dx.doi.org/10.5539/jms.v7n1p64

\begin{abstract}
The current situation facing business organizations is characterized by diverse work environments with continuous change and development. Todays organizations seek to keep pace with this continuous development and operate to maintain their current business through the ability to effectively respond to change, and to create competitive advantage based on the existence of qualified human capital that contribute to the creation of organizational sustainability in the business sector. Talented human capital, with special skills, has the potential to create confidence and integration among the staff and top management, leading to organizational growth and continuation (Kurucz, 2013). The emergence of a set of challenges in the knowledge economy has had a clear reflection on business organizations which have begun to search for new mechanisms to compete and insure their existence in the business world. Hence, the importance of the concept of competitive advantage, based on human capital, as a necessary requirement to deal with the challenges faced by local, regional or international organizations (Global Institute, 2011). Where competitive advantage based on human capital is the main generator of new ideas, development of old ideas, and contribution to aid in organizational abilities to expand their current market share as well as maximizing value. Competitive advantage based on talented human capital allows organizations to be able to seize new opportunities and achieve permanence and future continuity (Thomas, 2014). This study aimed to look at the impact of competitive advantage through intellectual capital investment as one of the elements in the creation of organizational sustainability in the Jordanian Telecommunications Companies sector. Simple and Multiple regression was used for data analysis and testing the hypotheses of this research .This study has reached a set of results that previous studies reinforced in this area such as: Competitive advantage based on a distinct capital is the optimum method that should be used in telecommunications companies since it contributes to the optimal investment of human capital. This leads to optimum organizational sustainability for companies in various fields and also contributes to the achievement of a company's mission and vision of the future.
\end{abstract}

Keywords: competitive advantage, human capital, organizational sustainability

\section{Introduction}

The concepts of sustainability and competitive advantage have received great attention from researchers due to the successful role that they are playing in achieving high organizational performance, which is an essential base for sustainable progress, development, and growth. Various fields of life are characterized by change and are closely linked to the style of work adopted, and the extent of understanding of the organization's psychology. The influence of achieving a reasonable balance between building a human capital-oriented competitive advantage and maintaining organizational sustainability needs (i.e., sustainable growth) should be taken into account by the business organization (Elizabeth, 2013). To ensure continuous growth, development and an innovative capability, business organizations should find the most suitable work mechanisms, based on competitive advantage elements, to determine the path to create stable and efficient organizational sustainability and encourage the development of strategic thinking (Cham, 2004). These steps will definitely help organizations handle the expected challenges they might face in the future, and preserve organizational efficiency, effectiveness, and survival under a changing and disturbed environment (Bani Issa, 2006). The emergence of the sustainability concept has received considerable attention by researchers and business organizations, especially 
the human capital concept, due to the intensive competition in the business field. The increase of environmental uncertainty and the emergence of a knowledge economy have played an influential role in the communications revolution and the rising information deployment phenomenon (Salman, 2009). Therefore, business organizations began looking for new mechanisms to be used in global competition as a prerequisite to ensure survival in the business world. In light of these local, regional and international challenges, human capital has been considered as a necessary element to help business organizations to be able to handle these challenges (Oasis, 2015). Human capital encompasses all individuals who have the knowledge and organizational capabilities that enable them to create new ideas and improve the old ones in order to facilitate the expansion of the organization's market share .This would insure consolidation of the organization's strengths, eliminate its weaknesses and boost its competitive advantage. Therefore, it would be relevant to conclude that organizational survival actually relies upon a continuous implementation of sustainable development planning (Catrin, 2011). Jordan is categorized as one of those countries which are suffering from a scarcity in its natural resources. This fact has urged the Jordanian government to pay great attention to the development of the country's human resources as the most important asset for sustainable economic growth. To achieve this objective the Jordanian government has allocated a considerable percentage of its annual budget to education, this was in parallel with a large investment made by the private sector also, especially in the last two decades. According to the Jordanian Ministry of Higher Education, Jordan has met its national educational ambitions and has achieved the expected output of its investment in human capital (Jordanian Ministry of Higher Education and Scientific Research, 2004). Based on what has been stated previously, it is reasonable to suggest that human resources are the most valuable national resource in the Jordanian economy and the core of its national competitive advantage. This denotes very clearly the important role of Jordanian human capital in the achievement of business sustainability in all sectors of the Jordanian economy.

\section{Methodology of the Study}

\subsection{Problem Statement}

Competitive advantage plays an important role in business organizations through helping them to survive, continue and maintain their current functions by creating sustainability in the business sector (Kurucz, 2013). Organizational objectives cannot be fully achieved without the attainment of competitive advantage based on the existence of intellectual capital and not just the reliance on equipment, buildings or appliances (David, 2015). However, the human capital investment requires wise and sound leadership capacity which recognize the importance of the human element and its components, and which have the ability to influence it in a positive way. Sound leadership of the human capital investment will accomplish conversion into competitive advantage, aiding in the creation of organizational sustainability and achievement of the organization's objectives (Al-Dahan, 2005). Hence, the questions of the study can be developed through the idea that human capital investment is an essential means to create competitive advantage for the organization and to enable it to continue and create organizational sustainability in the best way possible, enabling the organization to achieve its vision of the future. In order to counter the above problem methodically, the following questions were formulated:

- What is the level of the human capital investment in the Jordanian Telecommunications Companies Sector?

- Does the human capital investment contribute in the creation of competitive advantage in the Jordanian Telecommunications Companies Sector?

- What is the effect of the presence of competitive advantage based on human capital, in creating organizational sustainability and its elements to continuity and success in the Jordanian Telecommunications Companies Sector?

\subsection{Objectives of the Study}

The main objective of this study is to understand the impact of competitive advantage through intellectual capital investment as one of the elements in the creation of organizational sustainability in the Jordanian Telecommunications Companies Sector. From this main objective we can design the following objectives:

A. Create a theoretical framework to identify competitive advantage and organizational sustainability in terms of the concept, importance and dimensions.

B. Identify intellectual capital in terms of the concept, importance and elements.

C. Clarify the relationship between the variables above.

D. Identify the level of competitive advantage application in the Jordanian Telecommunications Companies Sector. 
E. Identify the level of human capital investment in the Jordanian Telecommunications Companies Sector.

F. Identify the impact of competitive advantage presence, based on human capital, in creating organizational sustainability in the Jordanian Telecommunications Companies Sector.

G. Submission of proposals and recommendations for decision-makers in the Jordanian Telecommunications Companies Sector which may benefit them in their field.

\subsection{Importance of the Study}

The importance of the study stems from the significance of the study sector, which is the Jordanian Telecommunications Companies sector. This sector is made up of the leading companies in the Jordanian economy and plays a prominent role in the economic, social, intellectual and technological achievements in Jordanian society (Al-Sakarneh, 2005). The study's importance comes from the development and progress of this sector, and is as follows:

- Importance of the study for researchers and academicians:

This study is considered as a reference for researchers and academicians in Jordan and the Arab world, where this study will provide theoretical and practical frameworks regarding the role of intellectual capital in the creation of competitive advantage, to achieve organizational sustainability. This study constitutes the base for researchers and academicians to launch larger fields of research and investigation on competitive advantage and organizational sustainability in this, and other sectors.

- Importance of the study for the directors in the Jordanian Telecommunications Companies sector:

This study provides a contemporary reference which shows the administrators and decision-makers in the Jordanian Telecommunications Companies Sector how to invest intellectual capital in the creation of competitive advantage to achieve organizational sustainability in their companies, so as to generate new ideas to aid in the achievement of organizational objectives.

- Importance of the Study for Employees in the Jordanian Telecommunications Companies sector:

This study provides telecommunications service providers a vision regarding the role of intellectual capital investment in the creation of competitive advantage, and in the achievement of organizational sustainability in order to accomplish their business objectives, as well as generating new ideas for discussion in the Jordanian Telecommunications Companies Sector.

\subsection{Model of the Study}

Independent Variable

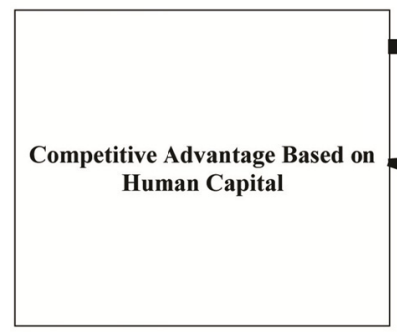

Dependent Variable

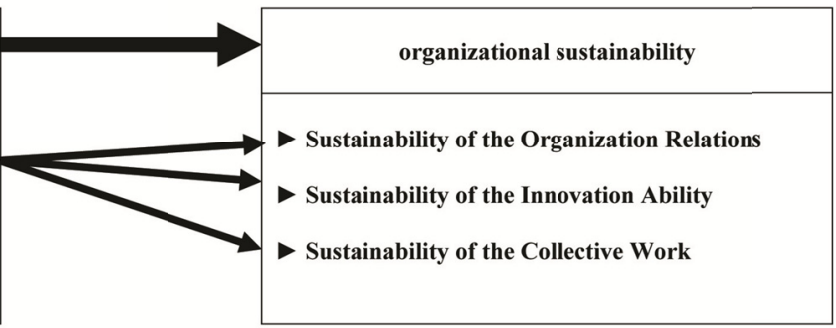

Figure 1. Model of the study

Note. Prepared by the researcher.

\subsection{Hypotheses of the Study}

Hypotheses of this study have been formulated according to the question of the study, its objectives and its model.

The main hypothesis is:

H0: There is a statistically significant impact for competitive advantage based on human capital, to achieve organizational sustainability in the Jordanian Telecommunications Companies Sector.

From this hypothesis we can formulate the following sub-hypotheses:

H1: There is a statistically significant impact for competitive advantage based on human capital, to achieve sustainability of organizational relations in the Jordanian Telecommunications Companies Sector. 
H2: There is a statistically significant impact for competitive advantage based on human capital, to achieve sustainability from the innovation ability in the Jordanian Telecommunications Companies Sector.

H3: There is a statistically significant impact for competitive advantage based on human capital, to achieve sustainability from the collective work in the organization within the Jordanian Telecommunications Companies Sector.

\subsection{Population of the Study}

The population of the study consists of the employees in companies who work in the Jordanian Telecommunications Companies Sector which amounted to (3) companies, namely (Zain, Orange, \& Umniah). The total number of employees reached therein (19000) and through the determination of employees who meet the human capital characteristics, (500) employees were identified, as representing the population of the study.

Sample of the Study:

Based on statistical equations used to determine the size of the sample (120) persons have been identified and were distributed as follows:

Table 1. Sample of the study

\begin{tabular}{ll}
\hline Name of the Company & Number of Distributed Questionnaires \\
\hline Zain Company & 40 \\
Orange Company & 40 \\
Umniah Company & 40 \\
\hline Total & $\mathbf{1 2 0}$ \\
\hline
\end{tabular}

\subsection{Method of Data Collecting}

The means of collecting information were divided into two parts:

\section{- First Part:}

The researcher conducted an audit and survey of the various theoretical and field studies related to competitive advantage, human capital and organizational sustainability. Scientific books and journals, Arabic and foreign, master's and doctoral theses, in addition to reliable information on the Internet were reviewed.

\section{- Second Part:}

A questionnaire was developed to reflect the role of human capital in the creation of competitive advantage and its impact on achieving organizational sustainability. The questionnaire was developed after reviewing questionnaires used in previous studies, and it was presented to a number of arbitrators to ascertain the viability of the content. All the necessary amendments were made to the paragraphs of the questionnaire before it was distributed to the study sample, which consisted of the staff of Jordanian Telecommunications Companies Sector covered by the research. The Likert Scale was used to measure the questionnaire content as follows:

(1) For the Strongly Agree, (2) For the Agree, (3) For the Neutral, (4) For the Disagree, (5) For the Strongly Disagree

As for the statistical methods used, the Statistical Package for Social Sciences (SPSS) has been used and will be explained in detail in the chapter concerning this aspect.

\subsection{Definitions of the Study Variables}

The study included many of the main variables as presented in the model of the study. Explanation of these variables for clarification is as follows:

- $\quad$ Competitive Advantage:

The ability and capabilities possessed by the organization in all its elements, through which it can make something of high value that the competitors cannot imitate or offer better.

- Intellectual Capital:

The process of intellectual ability capable to generate new and appropriate ideas, possessing a high level of quality, and the ability to achieve equality and harmony between the various components to reach the desired objectives, by employing and investing this intellectual ability properly for the benefit of the organization. 


\section{- Human Capital:}

A set of knowledge, experience, capabilities and skills for a group of employees in the organization, capable of achieving distinctive creations and solving traditional and non-traditional problems based on tacit and apparent knowledge.

\section{- Organizational Sustainability:}

The process of maintaining and creating a state of sustainability and continuity of the organization, in various fields in an unstable environment, while achieving objectives both efficiently and effectively.

\section{- Sustainability of the Organization Relations:}

The ability of an organization to communicate and to create reciprocal relations with the various parties associated with the organization.

\section{- Sustainability of the Innovation Ability:}

A set of resources, skills and abilities held by the employees, which continuously contribute to the creation of new ideas and innovative techniques that enhance the organization's performance and achieve its competitive advantage.

\section{- Sustainability of the Collective Work:}

A set of organizational management processes which lead to continuous completion of work through use of work teams, emphasizing collectivism as a managerial trait in achieving objectives.

\section{The Theoretical Framework}

\subsection{Competitive Advantage}

The subject of competitive advantage is highly attractive to a large number of researchers because of its impact in all areas of the organization, since competitive advantage is one of the most important factors affecting the success of organizations (Al-Dahan, 2005). As a result of the growing complexities in the business environment, and the increase in the intensity of competition between organizations, the need for organizations to possess unparalleled indicators has emerged. Organizations must occupy a leading position in the market through their ability to provide a better product or service, as compared to the competition. There are many concepts of competitive advantage, including the distinction of the organization as compared to other organizations in the same field (Bradshaw, 2014), as well as the pursuit of the organization to own special attributes that distinguish them from other organizations working in the same field (Wei, 2015). From the afore mentioned, it can be said that competitive advantage is the ability and capabilities possessed by the organization in all its elements through which it can make something of high value that the competitors cannot imitate or offer better, and is achieved through referring to a cognitive processes with clear managerial methodology. The possession of competitive advantage by the organization can help it to develop the means and methods to meet the challenges of the market, as well as the ability to meet the needs of customers, leading to the success of the organization. An organization with competitive advantage uses empowerment strategies and emphasizes the possession of the factors of successful production, fundamental capabilities and knowledge of the factors in the external environment, in addition to building integration, which contributes to the expansion of the value chain, enabling it to achieve its survival and continuity (Barnett, 2007).

\subsection{Human Capital}

The contemporary trends in modern management include new subject features that care about intellectual assets more than the physical assets, since maximizing the physical assets comes as a result of the availability of intellectual assets. This new subject is human capital, which has become, in the era of technology, the real stimulus in the success of organizations (Ching-Fu, 2015). Human capital is the intellectual ability capable of generating new ideas, appropriate processes and a high level of quality as a main stimulus for sustainable growth and achieving sustainable development, which in turn contribute to achieving the optimum investment for different resources to reach the objectives (Smith, 2007). Human capital is also the driving force of competitive advantage for business today, where human capital represents the innate capacity acquired in individuals which lead to an increase in the economic value added in all areas of business, if properly invested. As a result of the significance of this subject, researchers in Administrative Sciences have given great importance to human capital, especially in developing countries (Patrick, 2015), where they provide a lot of definitions in order to determine its concept. Some consider human capital as part of organizational work, others view it as including a set of components associated with the employees, a third group sees that it includes the education, experience and skills possessed by them, while some consider it as directly linked to the work (Pennington, 2015). 


\subsection{Importance of Human Capital}

The human element is the basis for an organization's existence and development, and it supports the organization's success and continuity (Jounes, 2013). Human capital plays a key role in dealing with the problems faced by the organization, and the development of appropriate solutions that lead to meeting the challenges faced by the organization (Noe, 2009).

It is a fact that human capital is the main factor that leads to the organization's success, and not buildings, equipment or trademarks (Decenzo, 2005). Thus, human capital has great significance in the success, continuity and survival of organizations. Below is a detailed explanation of this importance:

Leading companies develop strategies related to human capital, which are considered of utmost importance for identifying and seizing appropriate opportunities through skills and knowledge of talented employees with entrepreneurial abilities that result in achieving competitive advantage. Kurues (2013) confirmed that human capital is the main arm of the organization in today's world. Intellectual assets represent the hidden force that ensures the survival of the organization and its success and profitability, by working to focus on the main idea that should be addressed, while drawing from the support and innovation policies of human capital (Helen, 2015).

Human capital achieves the strategic objectives associated with improving work performance and development of organizational culture, to reach the creativity and innovation which leads to the success and survival of the organization (Dessler, 2003). The survival, growth and continuity of the company depend on the ability of employees to provide the necessary and important knowledge for survival, i.e., on the human capital that they own. In addition to this, the importance of human capital emanates from achieving three basic necessities which include necessity for success, necessity to create new knowledge and the necessity to achieve competitive advantage, through the ability to use characteristics convertible to innovations of great significance, to help decision-makers to take decisions related to sustainable growth in the organization (Helen, 2015).

\subsection{Organizational Sustainability}

The subject of sustainability is one of the modern subjects in business that has received considerable attention from researchers. Achieving profitability, increasing market share and achieving entrepreneurship and distinction are no longer the main subjects in an unstable environment. Organizations look beyond and focus on creating a state of sustainability and continuity and maintaining the current business through the ability to meet the current needs for sustainable growth (Fernandez, 2012) as well as the ability to be superior to their competitors. This requires the organization's attention to the sustainability of competitive advantage now and in the future (Ramazan, 2009) and in various aspects such a: sustainability of the organization's relations, sustainable ability for innovation and sustainability of collective work, and its association to the elements of its competitive advantage that contribute to this state of achievement, in which its human capital constitutes the key element in its continuation.

Many researchers have defined the concept of sustainability where White (2013) defined it as the process of creating a continuous value for current and future generations. Landrum (2009) enhanced this concept when he said "The organization's ability to maintain the organization's resources, assets and funds over the long term". Jones (2016) went on to say that it is the organization's ability to remain in the exercise of their activities in the long term and to achieve high growth rates. Michael (2015) said it is the organization's ability to continue and survive as a strong organization in the environment in which it operates long-term with the necessity of the presence of indicators reinforcing this continuation to confirm the increase of this force.

The creation of organizational sustainability requires the availability of a set of requirements as defined by (Barmwel, 2010) the most prominent are: the existence of the organization's continuation indicators, high rates of growth, attracting the best customers, achieving staff satisfaction and loyalty, optimum use of resources, supporting competitive ability, searching for points of strengths, weaknesses, opportunities and threats, and a continuous commitment to the innovation processes. It also includes working to overcome the obstacles of organizational sustainability represented in multiple measurements to measure the sustainability, government policies, lack of consistency between the sustainability and the business sector, the difficulty of distinguishing between the opportunities and threats in the future, and lack of knowledge of ways and means to motivate employees that participate in creating competitive advantage based on human capital through the use of organizational sustainability (OSM) (Michael, 2015). For the success of the organization, a set of points must be taken in to account when formulating sustainability strategy, these include: determining the motives of work and identifying the organization's vision clearly, in addition to understanding the current organization's position and the development of the workers capacity, and finally, determining the plan of action needed to create 
sustainability and reinforcing it to create a competitive advantage based on human capital as the basis or starting point in creating organizational sustainability that reinforces institutional behavior among employees. The following figure illustrates these elements:

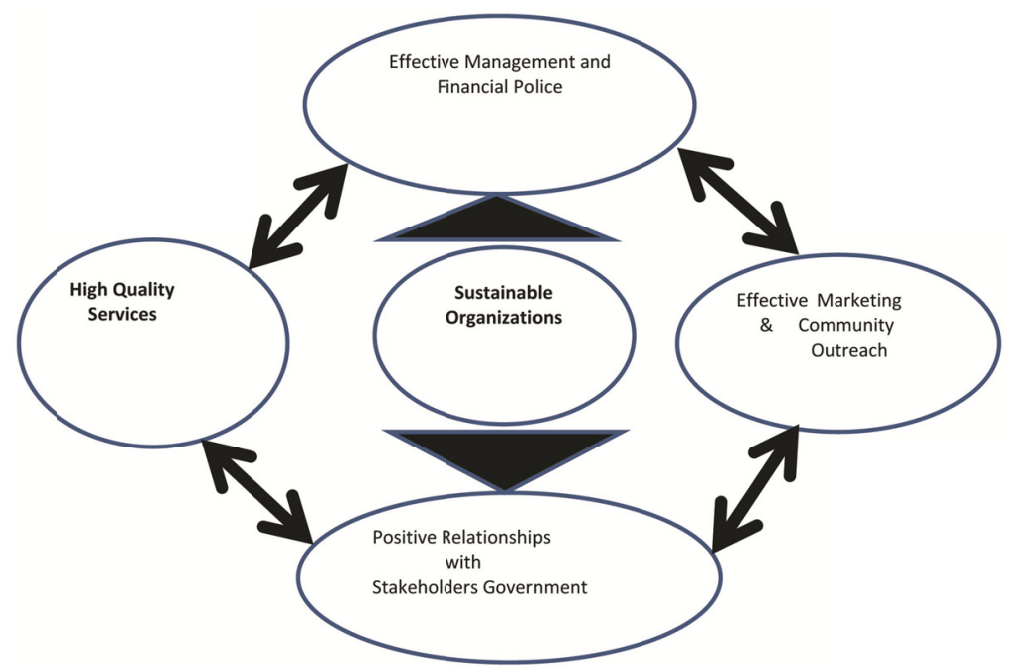

Figure 2. Elements of organizational sustainability

Note. Prepared by the research.

\section{The Relationship between Competitive Advantage Based on Human Capital and Organizational Sustainability}

This study model was comprised of two main variables that are: the independent variable which is competitive advantage based on human capital, and the dependent variable which is organizational sustainability. In order to achieve the objective of this study, it is necessary to clarify the basic connection between these two variables:

From the viewpoint of the researchers, competitive advantage based on the role of human resources, has a positive and significant impact on the elements of organizational sustainability, and their dimensions that lead to the achievement of the organization's success and continuity. This competitive advantage leads to the possession of quality based on building sustainability policies that are related to the development of creative behavior (Thomas, 2014), and that contribute to overcome the barriers to competitive sustainability embodied in:

1) The negative effects faced by the human element, which is reflected on its competitive advantage, constituting an obstacle to organizational sustainability.

2) The difficulty in obtaining a variety of workers to invest this diversity in the work, and place it in a framework that ensures the success and the achievement of organizational sustainability.

3) The difficulty of perception of the employees feelings and understanding their attitudes, their interests, their needs and their personal and practical requirements, in order to create the positive organizational climate needed for competitive advantage, which will lead to successful organizational sustainability in its different types: the organization relations sustainability, innovation ability sustainability and collective work sustainability, that produce an environment for growth and development based on creativity, innovation, motivation, incentives and sound moral behavior (Slaus \& Jacobs, 2001; Stoner et al., 2004).

4) Work to face globalization that has changed a great deal of the roles of organizations (Kielstra, 2008), and to focus on addressing the economic reasons for the question of organizational sustainability and to achieve economic objectives (Serafeimn, 2011).

5) Reduce the risks of energy use, including contributing to the promotion of trademarks and the increase of competitive advantage, that reinforces the continuation of the organization in the creation of sustainable development and the preservation of its current and future business (Sustainable growth), leading to improved financial and investment opportunities (Chang, 2016).

6) Deficiencies in the educational institutions policies related to sustainable development, that contribute 
to the creation of human resources required to achieve sustainable growth in the organization and society as a whole (Ramazan, 2009).

Overcoming these obstacles will enable the organization to build an organizational sustainability strategy model, based on the availability of competitive advantage relying on human capital to achieve profitability, obtain a high return on investment and remove restrictions on various resources, which constitute challenges facing organizations (Kuruez, 2013). The following figure illustrates this relationship:

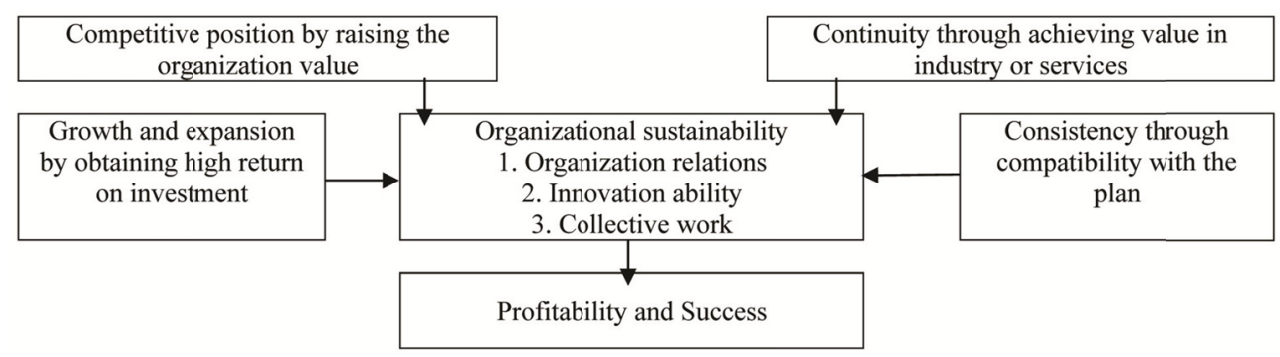

Figure 3. The relation between sustainability and profitability

Note. Prepared by the researcher.

\section{Applied Study}

This section includes the results of the study and the statistical analysis, simple and multiple regressions will be used as follows:

\subsection{Test of the Main Hypothesis}

(There is a statistically significant impact for competitive advantage based on human capital to achieve organizational sustainability with its elements in the Jordanian Telecommunications Companies Sector).

To test this hypothesis, multiple regression analysis was conducted and the following table shows the results:

Table 2. Result of multiple regression analysis: regressing CA variables against OS

\begin{tabular}{lllll}
\hline Correlation Coefficient & Determination Coefficient & Beta Coefficient & Value & Signification \\
$\mathrm{R}$ & $\mathrm{R} 2$ & $\mathrm{~B}$ & $\mathrm{~F}$ & $\mathrm{Sig}$ \\
\hline 0.56 & 0.31 & 0.80 & 43.31 & 0.00 \\
\hline
\end{tabular}

Table 2 shows that the Correlation Coefficient value for the impact of competitive advantage based on human capital on organizational sustainability, with its three dimensions amounted to (0.56) and the value of $\mathrm{F}$ amounted to (43.31), which is an indicator at the level of (0.05) and thus the hypothesis stipulating that the existence of the impact of competitive advantage based on human capital on organizational sustainability with its dimensions is accepted (sustainability of organization relations, sustainability of innovation ability, sustainability of collective work). Also, the above table shows that the beta value is (0.80), which reflects the positive impact and is also evident through value of (R2). That competitive advantage explains the value of (31\%) of the variance, and (69\%) is due to other factors.

\subsection{Test of the First Sub-hypothesis}

(There is a statistically significant impact for competitive advantage based on human capital to achieve sustainability of the organizational relations in the Jordanian Telecommunications Companies Sector).

Table 3. Regression test results of competitive advantage impact on organization relations sustainability

\begin{tabular}{lllll}
\hline $\begin{array}{l}\text { Correlation Coefficient } \\
\mathrm{R}\end{array}$ & Determination Coefficient & Beta Coefficient & Value & \multicolumn{2}{l}{$\begin{array}{l}\text { Signification } \\
\text { Sig }\end{array}$} \\
\hline 0.39 & $\mathrm{R} 2$ & $\mathrm{~B}$ & $\mathrm{~T}$ & 0.00 \\
\hline
\end{tabular}

Table 3 shows that the Correlation Coefficient value for the impact of competitive advantage based on human capital on organization relations sustainability amounted to (0.39) and the value of T amounted to (8.31), which 
is an indicator at the level of (0.05). Thus, the hypothesis stipulating that there is a statistically significant impact for competitive advantage based on human capital to achieve sustainability of the organizational relations in the Jordanian Telecommunications Companies Sector is accepted. Also, the above table shows that the beta value is (0.39), which reflects the positive impact and is also evident through value of R2 which reflects that competitive advantage explains the value of $(15 \%)$ of the variance, and $(85 \%)$ is due to other factors. This confirms the validity of the proposed model in the study.

\subsection{Test of the Second Sub-hypothesis}

(There is a statistically significant impact for competitive advantage based on human capital to achieve sustainability of the innovation ability in the Jordanian Telecommunications Companies Sector).

Table 4. Regression test results of the competitive advantage impact on the innovation ability sustainability

\begin{tabular}{lllll}
\hline Correlation Coefficient & Determination Coefficient & Beta Coefficient & Value & Signification \\
$\mathrm{R}$ & $\mathrm{R} 2$ & $\mathrm{~B}$ & $\mathrm{~T}$ & $\mathrm{Sig}$ \\
\hline 0.52 & 0.27 & 0.52 & 11.90 & 0.00 \\
\hline
\end{tabular}

Table 4 shows that the Correlation Coefficient value for the impact of competitive advantage based on human capital on innovation ability sustainability amounted to $(0.52)$ and the value of $(\mathrm{T})$ amounted to $(11.90)$, which is an indicator at the level of $(0.05)$ and thus the hypothesis, stipulating that there is a statistically significant impact for competitive advantage based on human capital to achieve sustainability of the innovation ability in the Jordanian Telecommunications Companies Sector, is accepted. Also, the above table shows that the beta value of (0.52), reflects the positive impact, and is also evident through value of $\mathrm{R} 2$, that competitive advantage explains the value of (27\%) of the variance, and (73\%), is due to other factors. This confirms the validity of the proposed model in the study.

\subsection{Test of the Third Sub-hypothesis}

(There is a statistically significant impact for competitive advantage based on human capital to achieve sustainability of the collective work in the organization within the Jordanian Telecommunications Companies Sector).

Table 5. Regression test results of the competitive advantage impact on the collective work sustainability

\begin{tabular}{lllll}
\hline Correlation Coefficient & Determination Coefficient & Beta Coefficient & Value & Signification \\
$\mathrm{R}$ & $\mathrm{R} 2$ & $\mathrm{~B}$ & $\mathrm{~T}$ & $\mathrm{Sig}$ \\
\hline 0.36 & 0.17 & 0.36 & 7.52 & 0.00 \\
\hline
\end{tabular}

Table 5 shows that the Correlation Coefficient value for the impact of competitive advantage based on human capital on collective work sustainability in the organization amounted to $(0.36)$, and the value of $(\mathrm{T})$ amounted to (7.52), which is an indicator at the level of (0.05) and thus the hypothesis, stipulating that there is a statistically significant impact for competitive advantage based on human capital to achieve sustainability of the collective work in the organization within the Jordanian Telecommunications Companies Sector, is accepted. Also, the above table shows that the beta value of $(0.36)$, reflects the positive impact. It is also evident through value of R2 that competitive advantage explains the value of (17\%) of the variance, and (83\%) is due to other factors. This confirms the validity of the proposed model in the study.

\section{Discussion of the Results}

The results have shown that human capital has a great impact on the creation of competitive advantage for the telecommunication companies in Jordan, where human capital operates on the creation of competitive advantage. Human capital constitutes the base in its creation, and the use of this competitive advantage is working to achieve organizational sustainability for these companies. This leads them to possess sustainability in relation to other telecommunication companies with which they work, and with their customers. Achieving success and development of these companies appeared in the results of this study which amounted to the value of (T) is (8.31), shown in table 3. Also, sustainability in finding ability within these companies and their employees to generate new ideas, generation of new knowledge, characterized in the introduction of new ideas and the generation of creativity in all areas of their work, making them distinct permanently and continuously from the rest of the companies operating in the same sector or other sectors, and can be seen in the power of impact that 
appeared in the results of the study, which amounted to (11.90), table 4.

Furthermore, the creation of collective work sustainability, through the completion of business in the telecommunications companies in accordance with the action teams, has differentiated the companies from other companies and has had significant consequences for the success of the companies in achieving their objectives efficiently and effectively, where the impact value reached (7.52) as is shown in table 5. By looking at the overall condition of the companies, results have shown that creating competitive advantage, based on the existence of a distinct human capital, will contribute to creating and finding a state of sustainability and successfully achieving objectives.

\section{Conclusions and Recommendations of the Study}

\subsection{Conclusions of the Study}

In light of the results and discussion of the study, the conclusions are the following:

1) There is a positive impact of human capital on creation of competitive advantage in the Jordanian Telecommunications Companies Sector and will create excellence.

2) The existence of a competitive advantage for telecommunication companies based on human capital, constitutes the ability of these companies to create organizational sustainability and the continuation of success.

3) There is a positive effect of the presence of competitive advantage, based on the existence of efficient human capital, which contribute to the creation of sustainability in companies with relation to the various parties, both inside and outside these companies.

4) There is a positive effect of the presence of competitive advantage, based on the existence of efficient human capital, that contribute to the creation of sustainability in the ability of companies to generate knowledge, create new ideas, maintain innovation and find creative ideas that contribute to the company's development, progress and superiority over its competitors.

5) There is a positive effect of the presence of competitive advantage, based on the existence of efficient human capital, which contributes to the creation of collective work sustainability.

6) Organizations should locate human capital which contribute to creating distinction and find work mechanisms that contribute to the attraction of distinctive elements.

7) Organizations should contribute to the creation of the new work environment characterized by the presence of organizational sustainability in various areas of the telecommunication companies.

8) Organizations should find competitive advantage based on a distinct capital, which is the optimum method that should be used in telecommunications companies. While contributing to the investment of human capital optimally, and achieving optimum organizational sustainability in various fields, companies will also achieve their vision and mission of the future.

\subsection{Recommendations of the Study}

According to the conclusions of the study, the study recommends the following:

1) Work on the attraction of distinct human capital in Jordanian Telecommunications Companies Sector, as well as finding sophisticated training programs to enhance the skills, abilities and knowledge of human capital needed to create competitive advantage for the companies in which they work, which in turn will contribute to organizational sustainability.

2) Work on the creation of competitive advantage based on the existence of distinct human capital, able to create this advantage that contributes to the successful continuation of the Jordanian telecommunications companies and invests the human capital working therewith optimally, to achieve organizational sustainability for the companies in various fields and contributes to achieving the vision of the future.

3) Support the continuity of the organization's relationships through the creation of work mechanisms that focus on the advancement of the creation of continuous and well-developed relations, with various parties inside and outside the companies.

4) Allow employees to participate in developing strategy of the organization and expand the participation of the organizations employees in the process of making decisions related to their work. Allow them to participate in setting up the future plans that achieve distinctive and creative aspirations and lead to the achievement of sustainable development for the companies they work in. 
5) Provide a stimulating and favorable working environment for the development of the skills and abilities of employees in the organization through working to determine the affecting environmental elements and their impact, and developing means to help take advantage thereof.

6) Take into account the moral aspect when making decisions in the organization, build and create trust between the organization and employees and follow the methods that help to overcome the difficulties faced by the organization, in order to create the sustainable development of the Jordanian Telecommunications companies.

7) Discover new idea generating work mechanisms and adopt and apply them to create new knowledge and great achievements, which contribute to the continuity and superiority of the companies.

8) Adopt use of Action Teams, as an important means to accomplish objectives, and decrease the use of the old formulas in administrative work, in order to achieve the benefits of collective work in Jordanian telecommunications companies and to achieve overall organizational sustainability.

\section{References}

Al-dahan, O. et al. (2005). Modern management concepts. Amman, Jordan: Jordanian Books Center.

Alsakarneh, B. (2005). Entrepreneurship strategies and their role in achieving competitive advantage and improve the performance of telecommunications companies in Jordan. Master Theses, University of Amman Arab Higher Studies, Amman, Jordan.

Amazon, E. et al. (2009). The problem of sustainability of organizational success in public education institutions: A research on the education administration in Turkey. Procardia-Social and Behavioral Sciences, 1(1), 2092-2102. https://doi.org/10.1016/j.sbspro.2009.01.368

Bani Issa, A. (2006). The impact of transformational leadership on performance in public institutions in Jordan: A Field Study. Master Theses, University of Jordanian, Amman, Jordan.

Barnett, K., Mc Cormack, J., \& Conner's, R. (2007). Transformational Leadership in Schools Panacea Placebo or Problem. Journal of Education Administration, 39(1), 24-46. https://doi.org/10.1108/09578230110366892

Boudreau1, J. W., \& Ramstad, P. M. (2005). Talent ship, talent segmentation, and sustainability: A new HR decision science paradigm for a new strategy definition. Human Resource Management, 44(2), 129-136. https://doi.org/10.1002/hrm.20054

Bradshaw, C. J. A., \& Brook, B. W. (2014). Human population reduction is not a quick fix for environmental problems. Proceedings of the National Academy of Sciences of the United States of America, 111(46), 16610-16615. https://doi.org/10.1073/pnas.1410465111

Cham, J. M. (2004). Transformational or Transactional Leader. Sport Light, 24(2).

Chang, V. et al. (2016). Organizational Sustainability Modeling. International Journal of Information Management, 36(1).

Ching, F. U., \& Chang, C. F. et al. (2015). Knowledge Spillovers, Human Capital and Productivity. Journal of Macronomics, 47, 214-232. https://doi.org/10.1016/j.jmacro.2015.11.003

De Cenzo, D. A., \& Robbins, S. P. (2015). Fundamentals of Human Resource Management (8th ed.). John New York: Wiley \& Sons, Inc.

Dressler, G. (2003). Human Resource Management. New Jersey: prentice Hill.

Elizabeth, C. K. et al. (2013). Leadership Skills for a Sustainable World. Toronto: University of Toronto Press.

Fernandez-Feijoo, B., \& Silvia, R. (2012). Transparent Information System for Sustainability. A Sectorial Analysis. Procardia Technology Journal, 5, 31-39. https://doi.org/10.1016/j.protcy.2012.09.004

Helen, M. et al. (2015). Measuring the Impact of Innovative Human Capital on Small firms Propensity to Innovate. Research Policy, 44(4), 965-976. https://doi.org/10.1016/j.respol.2014.11.008

Jawad, S. (2000). Strategic management. Amman: Dar Hameid for publishing and Distribution Jordan, (In Arabic).

Jones, P. (2016). A quantitative evaluation of the sustainability or unsustainability of three tunneling projects. Tunneling and Underground Space Technology Journal, 51(January), 387-404.

Jounes, D. R. (2013). Organizational metaphor for ecological sustainability. Journal of Cleaner Production, 
48(June).

Kasasbeh, M. et al. (2010). The role of human resources management function in the learning organization: a case study on the Talal Abu-Ghazaleh in Jordan. Jordanian Journal in Business Administration, 6(1).

Kuruez, E. (2013). Reconstructing Value: Leadership Skills for a Sustainable World. Handbook of Complexity and Management.

Lozano et al. (2015). Teaching organizational change management for sustainability. Journal of Cleaner Production, 106(1).

Michael, L., Nicole D. L., \& Bryan, W. H. (2015). Sustainability Strategy in Constrained Economic Times. Long Range Planning Journal, 48(2), 63-68. https://doi.org/10.1016/j.lrp.2014.07.001

Morris, M. (2000). Entrepreneurial Intensity: sustainable advantages for Individuals organizations \& societies. USA: Quorum Book.

Noe et al. (2010). Human Resource Management: Gaining a Competitive Advantage. Boston, USA: Irwin.

Oasis, K. T., \& Simpllce, A. (2015). Intelligence, Human Capital and HIV/AIDS. Intelligence Journal, 53, 154-159. https://doi.org/10.1016/j.intell.2015.10.005

Patrick, G. et al. (2015). Performance Assessment Vulnerability, Human Capital and the Allocation of Aid among Developing Countries. World Development, 48(6), 366-373.

Pennington, A. et al. (2015). Early organizational diffusion of contemporary policies: Narratives of sustainability and Talent management. Procardia-Social and Behavioral Sciences, 213, 807-811. https://doi.org/10.1016/j.sbspro.2015.11.480

Ramazan, E., \& Serhat, S. (2009). The problem of sustainability of organizational success in public educational institutions: a research on the education administrators in Turkey. Procedia-Social and Behavioral Sciences, 1(1), 2092-2102. https://doi.org/10.1016/j.sbspro.2009.01.368

Siddiqui, R., \& Sultan, H. A. (2013). Impact of Emotional Intelligence on Employees Turnover Rate in FMCG. Organizations. Pakistan Journal of Commerce and Social Sciences, 7(2).

Smith, A., \& Smith, E. (2007). The role of training in the development of human Resource Management in Australian organizations. Human Resource Development International Journal, 10(3), 263-279. https://doi.org/10.1080/13678860701515208

The Ministry of Higher Education and Scientific Research—Jordan. (2004). Retrieved from www.Howard litwak.com

Thomas, A. N. et al. (2014). Organizational Sustainability Policies and Employee green behavior. Journal of Environmental Psychology, 38(June).

Wei, C., \& Qian, X. (2015). Human capital investment in children: An empirical study of household child education expenditure in China, 2007 and 2011. Journal of China Economic Review, 37, 52-65.

White, L., \& Noble, B. F. (2013). Strategic environmental assessment for sustainability: A review of a decade of academic research. Environmental Impact Assessment Review Journal, 42(42), 60-66. https://doi.org/10.1016/j.eiar.2012.10.003

\section{Copyrights}

Copyright for this article is retained by the author(s), with first publication rights granted to the journal.

This is an open-access article distributed under the terms and conditions of the Creative Commons Attribution license (http://creativecommons.org/licenses/by/4.0/). 